\title{
The Mode of Action of Berninamycin and the Mechanism of Resistance in the Producing Organism, Streptomyces bernensis
}

\author{
By JILL THOMPSON, ERIC CUNDLIFFE* AND \\ MICHAEL J. R. STARK \\ Department of Biochemistry, University of Leicester, Leicester LE1 7RH, U.K.
}

(Received 1 July 1981)

The mode of action of berninamycin on bacterial protein synthesis is related to that of thiostrepton, a dissimilar compound. Both antibiotics bind to the complex of 23S RNA with protein L11 and both affect various functions of the ribosomal A site. Also, Streptomyces bernensis and Streptomyces azureus (which, respectively, produce berninamycin and thiostrepton) possess similar ribosomal RNA methylases capable of rendering ribosomes resistant to these compounds. Resistance involves specific pentose-methylation of $23 \mathrm{~S}$ ribosomal RNA.

\section{INTRODUCTION}

Berninamycin is a highly modified cyclic peptide antibiotic produced by Streptomyces bernensis (Bergy et al., 1972). It contains two oxazole rings together with a novel pyridothiazolopyridinium chromophore, 'berninamycinic acid' (for the complete structure, see Liesch \& Rinehart, 1977).

Berninamycin is known to be a potent inhibitor of protein synthesis in Gram-positive bacteria (Reusser, 1969) and, in bacterial extracts, it inhibits the synthesis of polypeptides in response to homopolynucleotide 'messengers' or phage RNA. However, the levels of inhibition observed in vitro did not approach those attained in vivo, and when partial reactions of protein synthesis were examined, none of them was sensitive to the drug. These included charging of aminoacyl-tRNA, attachment of artificial messengers to ribosomes, non-enzymic binding of aminoacyl-tRNA to the ribosome-messenger complex and peptide bond formation. Also, there was no evident 'misreading' effect associated with the action of berninamycin (Reusser, 1969).

The present investigation arose from the unexpected observation that growth of $S$. bernensis was totally resistant to the action of thiostrepton - an antibiotic structurally dissimilar to berninamycin (Tori et al., 1981). Accordingly, we examined the mechanism of resistance to thiostrepton in $S$. bernensis and, also, compared the mode of action of berninamycin with that of thiostrepton.

Thiostrepton binds firmly to the 50S ribosomal subunit thus inhibiting bacterial protein synthesis. More specifically, the antibiotic perturbs various functions of the ribosomal A site involving the binding of non-ribosomal factors and of guanine nucleotides (for a review, see Gale et al., 1981). Such inhibitory effects of thiostrepton do not occur on ribosomes from Streptomyces azureus, which produces the drug, or on those from other actinomycetes which elaborate antibiotics similar in structure to thiostrepton. In these organisms, specific methylation of ribosomal RNA (rRNA) at a single, common site renders ribosomes totally refractory to the 'thiostrepton-group' of antibiotics (Thompson \& Cundliffe, 1980). In contrast, streptomycetes which do not produce thiostrepton-like antibiotics do not commonly possess such methylase activity. Thus, it would appear that possession of the 'thiostrepton- 
resistance methylase' might allow $S$. azureus to tolerate its product (Cundliffe, 1978). This was confirmed when a fragment of the genome of $S$. azureus was cloned in Streptomyces lividans and was shown to confer resistance to thiostrepton (Thompson et al., 1980). The resistant clones possessed the specific rRNA methylase activity referred to above (C. J. Thompson et al., unpublished observations).

We therefore wished to determine whether $S$. bernensis possesses rRNA methylase activity comparable with that which determines resistance to thiostrepton in $S$. azureus. In addition, we examined the mechanism by which $S$. bernensis tolerates its own product, berninamycin.

\section{METHODS}

Sources of materials. Berninamycin and Streptomyces bernensis UC 5144 were obtained from the Upjohn Company, Kalamazoo, Mich., U.S.A.; thiostrepton and Streptomyces azureus ATCC 14921 were from the Squibb Institute for Medical Research, Princeton, N.J., U.S.A.; micrococcin was kindly provided both by Dr James Walker, National Institute for Medical Research, Mill Hill, London, U.K. and by Dr Norman Heatley, Department of Pathology, University of Oxford, U.K. Radiolabelled materials were obtained from Amersham. $\left[{ }^{35} \mathrm{~S}\right]$ Thiostrepton was prepared by growth of $S$. azureus in broth containing $\left[{ }^{35} \mathrm{~S}\right]$ sulphate as described previously (Dixon et al., 1975). Elongation factor G (factor EF-G) from Escherichia coli was a generous gift from Professor James Bodley, Department of Biochemistry, University of Minnesota, Minneapolis, U.S.A.

Preparation of ribosomal components. Methods for the preparation of the following materials have been described previously: salt-washed ribosomes and post-ribosomal supernatant (Cundliffe et al., 1979), ribosomal subunits (Stark \& Cundliffe, 1979a), individual species of ribosomal RNA (Thompson et al., 1979), ribosomal core particles and split proteins (Cundliffe \& Thompson, 1981a). Ribosomal protein L11 was provided by Dr Jan Dijk and had been purified as described by Dijk \& Littlechild (1979). ' $4 \mathrm{M}-\mathrm{LiCl}$ core-50' particles were produced from $E$. coli $50 \mathrm{~S}$ ribosomal subunits by exposure to $4 \mathrm{M}-\mathrm{LiCl}$. One pmol equivalent of split proteins was defined as those proteins removed per pmol 50S subunits during conversion to cores. All materials used in these experiments were prepared from $E$. coli unless otherwise stated.

Preparation of 'crude methylase' from S. bernensis. Under conditions similar to those described below but using total rRNA from Streptomyces coelicolor as substrate and $S$-adenosyl-L-[methyl- $\left.{ }^{3} \mathrm{H}\right]$ methionine ([methyl$\left.{ }^{3} \mathrm{H}\right] \mathrm{SAM}$ ) as cofactor, RNA methylase activity was detected in post-ribosomal supernatant (S100) from $S$. bernensis. When $\mathbf{S} 100$ was fractionated using ammonium sulphate, all such methylase activity was found among those proteins precipitated by the salt between $50 \%$ and $70 \%$ saturation. This protein fraction, designated 'crude methylase', was re-dissolved in buffer containing $10 \mathrm{mM}$-Tris/ $\mathrm{HCl}\left(\mathrm{pH} 7.6\right.$ at $\left.20^{\circ} \mathrm{C}\right), 10 \mathrm{mM}-\mathrm{MgCl}_{2}$, $50 \mathrm{mM}-\mathrm{NH}_{4} \mathrm{Cl}, 3 \mathrm{mM}-2$-mercaptoethanol. It was stored as small samples at $-70^{\circ} \mathrm{C}$.

Enzymic binding of phenylalanyl-tRNA to ribosomes. This was carried out as described elsewhere (Stark \& Cundliffe, $1979 a$ ) except that $E$. coli ribosomes were used here and were incubated with drugs for 5 min at $20^{\circ} \mathrm{C}$ prior to the addition of polyuridylic acid [poly(U)]. Drug-free controls received only the solvent dimethyl sulphoxide (DMSO). $\left[{ }^{14} \mathrm{C}\right]$ Phenylalanyl-tRNA [513 $\mathrm{Ci} \mathrm{mol}^{-1}\left(18.98 \mathrm{TBq} \mathrm{mol}{ }^{-1}\right) ; 1090$ c.p.m. pmol ${ }^{-1}$ ] and the [EF-Tu-GTP] complex were mixed together for $5 \mathrm{~min}$ at $0^{\circ} \mathrm{C}$ before being added to the [ribosome $\left.\cdot \operatorname{poly}(\mathrm{U})\right]$ complex.

Synthesis of guanosine tetra- and pentaphosphates in vitro. This was carried out using $70 \mathrm{~S}$ ribosomes, unfractionated tRNA and crude stringent factor (all from $E$. coli) together with poly(U), GTP and [ $\gamma^{32}$ P]ATP (80 c.p.m. pmol $^{-1}$ ) as described elsewhere (Stark \& Cundliffe, $1979 \mathrm{~b}$ ). Ribosomes were incubated with drugs (or with DMSO) at $20^{\circ} \mathrm{C}$ for $10 \mathrm{~min}$ prior to the addition of other components of the reaction mixture as a 'cocktail'. After incubation at $37^{\circ} \mathrm{C}$ for $40 \mathrm{~min}$, nucleotide products were separated by chromatography on poly(ethyleneimine) cellulose plates and located by autoradiography. Radioactivity incorporated into guanosine penta- and tetraphosphates was determined by subjecting appropriate pieces of chromatograms to liquid-scintillation spectrometry (for details, see Stark \& Cundliffe, 1979b).

Binding of ${ }^{35}$ S $]$ thiostrepton to $50 S$ ribosomal subunits and to complexes of $23 S R N A$ with protein L11. (i) In the experiments summarized in Table $1(a)$, E. coli 50 S ribosomal subunits $(35 \mathrm{pmol})$ were incubated with berninamycin (controls received DMSO) for $10 \mathrm{~min}$ at $20^{\circ} \mathrm{C}$ before $\left[{ }^{35} \mathrm{~S}\right]$ thiostrepton (35 pmol; $890 \mathrm{c.p.m}$. $\mathrm{pmol}^{-1}$ ) was added for a further $10 \mathrm{~min}$ at $20^{\circ} \mathrm{C}$. Then, unbound drug was removed by adsorption to activated charcoal which was subsequently removed by centrifugation. Bound $\left[{ }^{35} \mathrm{~S}\right]$ thiostrepton in the supernatant was estimated by liquid-scintillation spectrometry. Except for the use here of buffers containing $10 \mathrm{~mm}-\mathrm{MgCl}_{2}$, these assays were carried out as described previously (Thompson et al., 1979). (ii) In the experiments relating to Table $1(b)$, 23S RNA (26 pmol) and protein L11 (170 pmol) were incubated together at $20^{\circ} \mathrm{C}$ for $10 \mathrm{~min}$ before addition of berninamycin etc. as described under (i) above. (iii) In the experiments relating to Table 4, the effect of methylation of 23S RNA using a crude extract of $S$. bernensis was investigated. Escherichia coli 23S RNA 
(15 pmol) was incubated at $35^{\circ} \mathrm{C}$ for the times indicated with 'crude methylase' from $S$. bernensis (see above) both in the presence and absence of $S$-adenosylmethionine (SAM; $0.5 \mathrm{mM}$ ). This was carried out in $18 \mu \mathrm{l}$ of buffer as described below for the methylation of core particles. Then, protein L11 $(40 \mathrm{pmol})$ was added together with $\left[{ }^{35} \mathrm{~S}\right]$ thiostrepton $\left(42 \mathrm{pmol} ; 39\right.$ c.p.m. pmol ${ }^{-1}$ ) and $72 \mu \mathrm{l}$ buffer containing $10 \mathrm{mM}$-Tris $/ \mathrm{HCl}\left(\mathrm{pH} 7.6\right.$ at $20^{\circ} \mathrm{C}$ ), $10 \mathrm{mM}-\mathrm{MgCl}_{2}, 50 \mathrm{mM}-\mathrm{NH}_{4} \mathrm{Cl}, 3 \mathrm{mM}-2$-mercaptoethanol. Incubation was continued at $20^{\circ} \mathrm{C}$ for $10 \mathrm{~min}$ before addition of activated charcoal and estimation of bound $\left.{ }^{33} \mathbf{S}\right]$ thiostrepton as described under (i) above.

Methylation of ribosomal core particles and reconstitution of $50 S$ subunits. $4 \mathrm{M}-\mathrm{LiCl}$ core-50 particles from $E$. coli ribosomes $(68 \mathrm{pmol})$ were incubated for $20 \mathrm{~min}$ at $35^{\circ} \mathrm{C}$ with 'crude methylase' from $S$. bernensis or with purified 'thiostrepton-resistance methylase' from $S$. azureus (Thompson \& Cundliffe, 1981) in $10 \mu \mathrm{l}$ buffer containing $25 \mathrm{mM}-\mathrm{N}$-2-hydroxyethylpiperazine- $N^{\prime}-2$-ethanesulphonic acid (HEPES)/KOH $\left(\mathrm{pH} 7.5\right.$ at $20^{\circ} \mathrm{C}$ ), $10 \mathrm{mM}$-Tris/ $\mathrm{HCl}\left(\mathrm{pH} 7.6\right.$ at $\left.20^{\circ} \mathrm{C}\right), 10 \mathrm{mM}-\mathrm{MgCl}_{2}, 50 \mathrm{mM}-\mathrm{NH}_{4} \mathrm{Cl}, 3 \mathrm{mM}-2$-mercaptoethanol. Incubation was at $35^{\circ} \mathrm{C}$ for $20 \mathrm{~min}$ both in the presence and absence of SAM $(0.5 \mathrm{mM})$. Samples containing 55 pmol cores were then added to 64 pmol equivalents of $4 \mathrm{M}-\mathrm{LiCl}$ split proteins and incubation was continued for $90 \mathrm{~min}$ at $50^{\circ} \mathrm{C}$ in $50 \mu \mathrm{l}$ reconstitution buffer $\left[20 \mathrm{~mm}\right.$-Tris $/ \mathrm{HCl}\left(\mathrm{pH} 7.6\right.$ at $20^{\circ} \mathrm{C}$ ), $20 \mathrm{mM}-\mathrm{MgCl}_{2}, 350 \mathrm{~mm}-\mathrm{NH}_{4} \mathrm{Cl}, 3 \mathrm{~mm}$ 2-mercaptoethanol]. The activity of reconstituted 50S ribosomal subunits was finally assayed both in synthesis of polyphenylalanine and in uncoupled hydrolysis of GTP by adding them directly to appropriate reaction mixtures. In all cases, the activity of reconstituted 50S subunits was assayed in the presence of an excess of native 30S subunits.

Synthesis of polyphenylalanine in response to polyuridylic acid. Reconstituted 50S ribosomal subunits $(12.5 \mathrm{pmol})$ were supplemented with native $30 \mathrm{~S}$ subunits $(32 \mathrm{pmol})$ and incubated for $10 \mathrm{~min}$ at $30^{\circ} \mathrm{C}$ with drugs (controls received DMSO) in $20 \mu \mathrm{l}$ buffer containing $14 \mathrm{mM}-\mathrm{Tris} / \mathrm{HCl}\left(\mathrm{pH} 7.6\right.$ at $20^{\circ} \mathrm{C}$ ), $10 \mathrm{mM}-\mathrm{MgCl}_{2}, 175$ mM- $\mathrm{NH}_{4} \mathrm{Cl}, 1.5 \mathrm{mM}-2$-mercaptoethanol. Then, post-ribosomal supernatant (S100) was added together with poly $(\mathrm{U})$ and other components necessary for cell-free protein synthesis. This was carried out under the conditions described by Cundliffe et al. (1979).

Hydrolysis of GTP dependent on ribosomes and factor EF-G, i.e. 'uncoupled' GTPase activity. Native 70S ribosomes or reconstituted $50 \mathrm{~S}$ subunits $\left(2.4 \mathrm{pmol}\right.$ ) were incubated at $30^{\circ} \mathrm{C}$ for $10 \mathrm{~min}$ with drugs (controls received DMSO; $1.5 \%, \mathrm{v} / \mathrm{v}$, final concentration) in $75 \mu \mathrm{l}$ buffer containing $15 \mathrm{mM}-\mathrm{Tris} / \mathrm{HCl}\left(\mathrm{pH} 7.6\right.$ at $\left.20^{\circ} \mathrm{C}\right), 10$ mM- $\mathrm{MgCl}_{2}, 80 \mathrm{mM}-\mathrm{NH}_{4} \mathrm{Cl}, 2 \mathrm{mM}-2$-mercaptoethanol. Reconstituted $50 \mathrm{~S}$ subunits then received a 10 -fold excess of native $30 \mathrm{~S}$ ribosomal subunits. All incubations were finally supplemented with $10 \mu \mathrm{l}$ of a mixture containing $50 \mathrm{pmol}$ factor EF-G and $9 \mathrm{nmol}\left[\gamma^{32} \mathrm{P}\right] \mathrm{GTP}\left[9.7 \mu \mathrm{Ci} \mu \mathrm{mol}^{-1}\left(359 \mathrm{kBq} \mu \mathrm{mol}^{-1}\right)\right.$; approximately $20 \mathrm{c.p} . \mathrm{m}$. $\mathrm{pmol}^{-1}$ ] in the above buffer. Incubation was at $30^{\circ} \mathrm{C}$ and GTP hydrolysis was followed by taking samples into perchloric acid and removing unhydrolysed GTP by adsorption to activated charcoal. Free [ $\left.{ }^{32} \mathrm{P}\right]$ phosphate was estimated by liquid-scintillation spectrometry (for details, see Stark \& Cundliffe, 1979a).

Methylation reactions involving the use of radiolabelled cofactor. Conditions were as for the non-radioactive methylation of core particles (above). Assay mixtures (100 $\mu \mathrm{l}$ total volume) contained 'crude methylase' from $S$. bernensis together with $2.5 \mu \mathrm{Ci}$ [methyl $\left.{ }^{3} \mathrm{H}\right] \mathrm{SAM}\left[500 \mathrm{mCi} \mathrm{mmol}^{-1}\left(18.5 \mathrm{GBq} \mathrm{mmol}^{-1}\right)\right]$ and one of the following substrates derived from $E$. coli: $23 \mathrm{~S}$ rRNA (42 pmol), 16S rRNA ( $77 \mathrm{pmol}), 5 \mathrm{~S}$ rRNA (52 pmol), $4 \mathrm{M}-\mathrm{LiCl}$ core- 50 particles $(68 \mathrm{pmol})$ or $50 \mathrm{~S}$ ribosomal subunits $(71 \mathrm{pmol})$. Samples $(20 \mu \mathrm{l})$ were removed at intervals (up to $20 \mathrm{~min}$ ) into ice-cold $5 \%(\mathrm{w} / \mathrm{v})$ trichloroacetic acid and, after $30 \mathrm{~min}$ at $0^{\circ} \mathrm{C}$, were filtered on Whatman $\mathrm{GF} / \mathrm{C}$ glass-fibre discs. Filters were dried and their radioactivity was estimated by liquid-scintillation spectrometry. The data in Table 5 all relate to incubations of 20 min duration, by which time incorporation of radiolabelled methyl groups was complete.

\section{RESULTS}

The present work commenced with the demonstration that ribosomes of Streptomyces bernensis were completely resistant in vitro to the effects of both berninamycin and thiostrepton. Those experiments are not described here in detail but the matter is taken up later. We therefore wished to ascertain whether ribosomal resistance to the two drugs was conferred via a common mechanism and, if so, whether this implied that berninamycin and thiostrepton normally bind to related ribosomal target sites. The latter point was examined first.

Thiostrepton binds firmly to a single site on the $50 \mathrm{~S}$ ribosomal subunits of sensitive bacteria and this binding site can be reconstructed in vitro using only 23S rRNA and ribosomal protein L11 (Thompson et al., 1979). As can be seen in Table 1, berninamycin competed, albeit feebly, with $\left.{ }^{35} S\right]$ thiostrepton for binding to such sites. However, in view of the avidity with which thiostrepton binds to its target and the large number of ribosome 
Table 1. Effect of berninamycin on binding of $\left[{ }^{35} S\right]$ thiostrepton to $50 S$ ribosomal subunits and to RNA-protein complexes

$\begin{array}{ccc}\text { Binding to: } & \begin{array}{c}\text { Molar excess of } \\ \text { berninamycin over } \\ \text { thiostrepton }\end{array} & \begin{array}{c}\text { Binding ratio* } \\ \text { (\% of control) }\end{array} \\ \text { (a) 50S ribosomal subunits } & 0 & 0.98(100) \\ & 12.5 & 0.95(97) \\ \text { b) 23S RNA plus protein L11 } & 125 & 0.96(98) \\ & 1250 & 0.85(86) \\ \text { 23S RNA (without protein L11) } & 0 & 0.71(100) \\ \text { pmol [ }{ }^{35} \text { S]thiostrepton bound per pmol 50S subunits }(a) \text { or per pmol 23S RNA (b). }\end{array}$

Table 2. Effects of antibiotics on enzymic binding of $\left[{ }^{14} \mathrm{C}\right]$ phenylalanyl-tRNA to E. coli ribosomes

\begin{tabular}{|c|c|c|}
\hline Drug added & $\begin{array}{l}\text { Molar excess } \\
\text { of drug } \\
\text { over ribosomes }\end{array}$ & $\begin{array}{c}{\left[{ }^{14} \mathrm{C}\right] \text { Phenylalanyl-tRNA }} \\
\text { bound (\% of control) }\end{array}$ \\
\hline DMSO (control) & - & $100^{*}$ \\
\hline Berninamycin & 100 & 83 \\
\hline Thiostrepton & 100 & 27 \\
\hline
\end{tabular}

* In controls, $0.2 \mathrm{pmol}\left[{ }^{14} \mathrm{C}\right]$ phenylalanyl-tRNA was bound per pmol ribosomes.

inhibitors which do not compete with it (our unpublished data), we do not doubt the significance of this inhibitory effect. Accordingly, we conclude that berninamycin binds to the complex of 23S RNA with protein L11. Possibly, berninamycin binds (but with lesser affinity) to the same site as does thiostrepton; alternatively, the two drugs might bind to adjacent sites. In the latter event, no statement can be made regarding the affinity with which berninamycin binds. Nor is it clear from these data whether ribosomes possess multiple binding sites for berninamycin. This point is discussed later.

Having ascertained that the two antibiotics bound to related target sites, we next examined the possibility that, like thiostrepton, berninamycin might inhibit functions of the ribosomal A site. Prominent among these is the accommodation of mRNA-cognate aminoacyl-tRNA prior to its involvement in peptide bond formation. Berninamycin and thiostrepton both inhibited the binding of phenylalanyl-tRNA to the ribosome in response to poly(U) in the presence of factor EF-Tu and GTP (Table 2). Again, the level of inhibition by berninamycin, while significant, was low.

The ribosomal A site also participates in reactions involving the supernatant factor EF-G. This protein normally functions during the translocation reaction of protein synthesis during which GTP is hydrolysed in stoichiometric fashion. Neither the factor nor the ribosome alone possesses GTPase activity but together, in the absence of other components necessary for protein synthesis, they catalyse multiple rounds of GTP hydrolysis. We therefore examined the effects of berninamycin on such 'uncoupled' hydrolysis of GTP which was already known to be inhibited specifically by thiostrepton (Pestka, 1970). As shown in Fig. 1(a), berninamycin slightly stimulated hydrolysis. This effect was maximal when the drug was employed at 100-1000-fold molar excess over ribosomes; lower drug inputs resulted in lower levels of stimulation. The physiological significance of this effect became apparent when we 

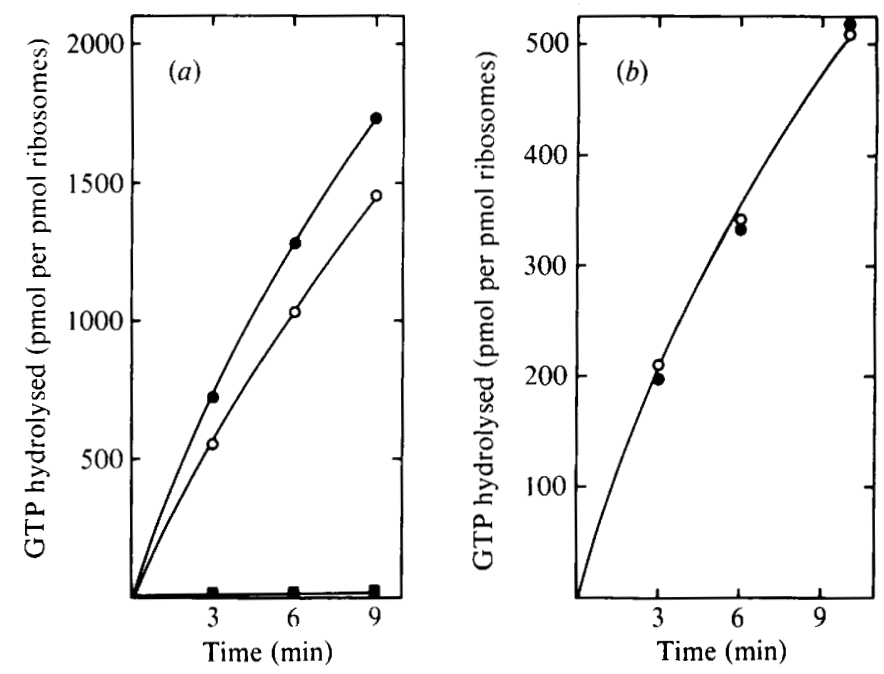

Fig. 1. Effects of antibiotics on factor-dependent GTPase activity of ribosomes from different bacteria Factor EF-G from $E$. coli was used together with $\left[\gamma_{-}{ }^{32} \mathrm{P}\right] \mathrm{GTP}$ and $70 \mathrm{~S}$ ribosomes from $(a) E$. coli and (b) B. megaterium strain MJ1 (thiostrepton resistant). Control incubations received DMSO; otherwise drugs were added at the indicated molar excesses over ribosomes: 0 , controls; $O$, berninamycin $(100: 1$ in $a, 700: 1$ in $b) ; \square$, thiostrepton $(3: 1)$.

utilized, in similar assays, the ribosomes from a thiostrepton-resistant mutant of Bacillus megaterium, namely strain MJ1. These ribosomes lack a protein which is physically and functionally homologous with $E$. coli protein L11 (Cundliffe et al., 1979; Stark et al., 1980). Uncoupled GTP hydrolysis catalysed by ribosomes from $B$. megaterium strain MJ1 together with factor EF-G from $E$. coli was completely unaffected by berninamycin (Fig. $1 b$ ). These data are readily reconciled with our conclusion (above) that protein L11 is a constituent of the berninamycin-binding site and with the subsequent observation (unpublished data) that thiostrepton-resistant mutants of $B$. megaterium (such as strain MJ1) are cross-resistant to berninamycin.

In other experiments (data not given), we determined that berninamycin did not reveal any latent GTPase activity either of ribosomes or of factor EF-G alone. Also, effects closely similar to those shown in Fig. 1 (a) could be reproduced using purified 50S ribosomal subunits from $E$. coli instead of $70 S$ particles. Thus, stimulation by berninamycin of uncoupled GTPase activity could not be attributed to the promotion of ribosomal subunit association (Modolell et al., 1971). Accordingly, we concluded that the effect arose as a result of the binding of berninamycin to its normal target site(s) within the ribosome.

Finally in this context, we examined possible effects of berninamycin on the ribosomal synthesis of guanosine penta- and tetraphosphates in response to stringent factor, mRNA and cognate deacylated tRNA. Production of these regulatory guanosine polyphosphates (the so-called 'magic spot' nucleotides) underlies the stringent control of RNA synthesis during amino acid starvation and involves pyrophosphate transfer from ATP on to the 3'-hydroxyl group of GTP or GDP. Thiostrepton is a potent inhibitor of this reaction (Pedersen et al., 1973) which apparently occurs in the ribosomal A site. Again, berninamycin was inhibitory, but not so strongly as thiostrepton (Table 3). These data reinforced our general conclusion that berninamycin acts in the ribosomal A site. However, since production of guanosine polyphosphates could, in principle, be hindered in a number of different ways, we were unable to determine precisely the mechanism of the observed inhibition.

We next examined the mechanism(s) of antibiotic resistance in Streptomyces bernensis, the producer of berninamycin. Growth of this organism is totally unaffected by berninamycin, 
Table 3. Effects of antibiotics on synthesis of guanosine penta-and tetraphosphates in vitro

$\begin{array}{lcc}\text { Drug added } & \begin{array}{c}\text { Molar excess } \\ \text { of drug } \\ \text { over ribosomes }\end{array} & \begin{array}{c}\text { Guanosine } \\ \text { polyphosphates formed } \\ \text { (\% of control) }\end{array} \\ \text { DMSO (control) } & - & 100^{*} \\ \text { Berninamycin } & 3 & 44 \\ \text { Berninamycin } & 20 & 48 \\ \text { Berninamycin } & 200 & 36 \\ \text { Berninamycin } & 350 & 40 \\ \text { Thiostrepton } & 3 & 10\end{array}$

\footnotetext{
* In controls, about $12 \%$ of the input $\left[\gamma_{-}{ }^{32} \mathrm{P}\right] \mathrm{ATP}$ was converted to guanosine polyphosphates: this represented about 70 pmol per pmol ribosomes.
}

thiostrepton or micrococcin (our unpublished observations). The latter compound was included in these studies since it had recently been shown to stimulate (more strongly than did berninamycin) the uncoupled hydrolysis of GTP on E. coli ribosomes (Cundliffe \& Thompson, 1981a). Initially, we prepared ribosomes from $S$. bernensis and from other Streptomyces species and employed them, together with post-ribosomal supernatant from $E$. coli, in the synthesis of polyphenylalanine directed by poly(U). Synthesis on ribosomes from $S$. bernensis or from $S$. azureus (the thiostrepton producer) was totally unaffected by berninamycin, thiostrepton or micrococcin even when drugs were employed at 100 -fold molar excess over ribosomes (data not given). In contrast, ribosomes from Streptomyces coelicolor (our standard reference streptomycete) were severely inhibited by these drugs at much lower inputs (for typical experimental details, see Thompson \& Cundliffe, 1980). Subsequently, in the presence of factor EF-G from $E$. coli, uncoupled hydrolysis of GTP on ribosomes from $S$. bernensis or $S$. azureus proved to be totally insensitive to the three drugs (even at elevated inputs), whereas, with ribosomes from $S$. coelicolor, results closely similar to those given in Fig. 1 (a) were obtained (data not given).

These data confirmed the significance of the stimulatory effect of berninamycin on factor-dependent GTP hydrolysis supported by sensitive ribosomes. They also pointed to similar characteristics of ribosomes from $S$. bernensis and $S$. azureus. We therefore examined extracts of $S$. bernensis for the possible presence of rRNA methylase activity similar to that known to determine resistance to thiostrepton in $S$. azureus. Results of the critical experiment establishing the presence of such an enzyme in S. bernensis are summarized in Fig. 2. Core particles prepared from $E$. coli $50 \mathrm{~S}$ ribosomal subunits were incubated with 'crude methylase' from $S$. bernensis (see Methods) or with the highly purified 'thiostrepton-resistance methylase' from $S$. azureus (Thompson \& Cundliffe, 1981) both in the presence and absence of SAM. Then, 50S ribosomal subunits were reconstituted by adding back to cores the missing 'split proteins'. Finally, native $30 \mathrm{~S}$ ribosomal subunits of $E$. coli were added and the activity of the resultant $70 \mathrm{~S}$ ribosomes was examined in polyphenylalanine synthesis. As seen in Fig. 2(a), methylation of cores by an activity present in extracts of $S$. bernensis resulted in complete resistance to berninamycin, thiostrepton and micrococcin. In contrast, when SAM was omitted from incubations, the reconstituted particles retained the characteristics of native $E$. coli ribosomes. Data obtained using the purified 'thiostreptonresistance methylase' from $S$. azureus are not presented here but were essentially similar to those shown in Fig. $2(a)$. The only notable difference was that, in drug-free controls, ribosomes reconstituted from methylated cores were equally as active as those produced from cores incubated in the absence of SAM. We have no ready explanation for the slight loss of activity of particles methylated in the presence of $S$. bernensis extract but we do not regard this as a serious defect in these experiments. 

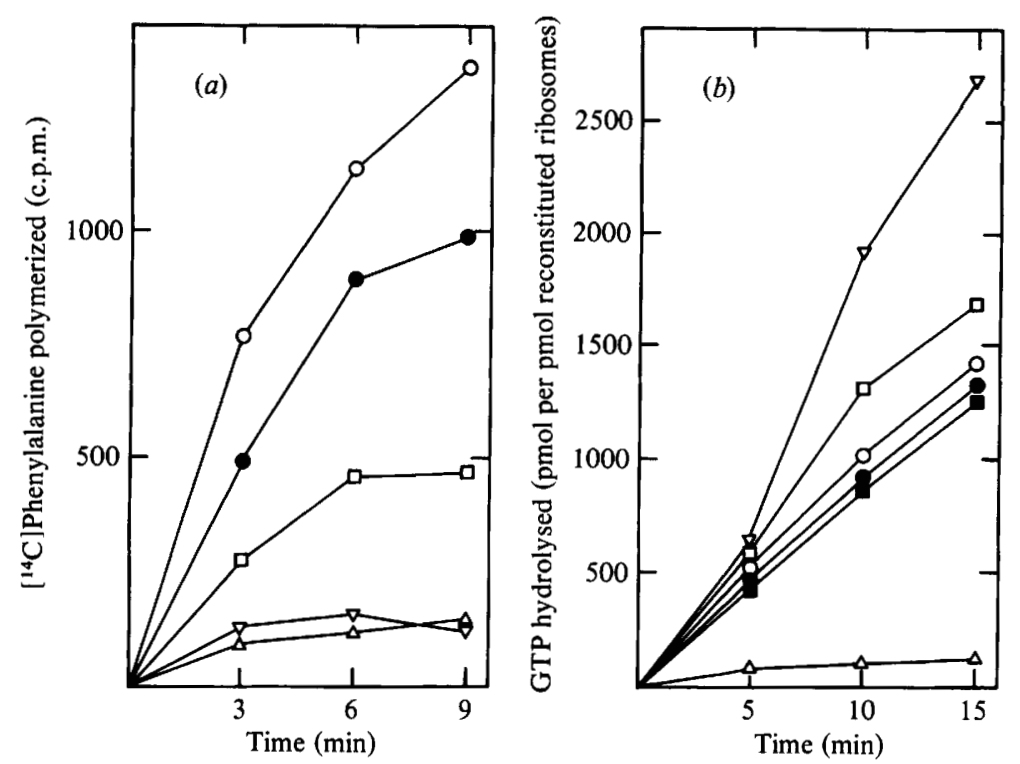

Fig. 2. Effects of antibiotics on the activities of reconstituted $E$. coli ribosomes following incubation of core particles with extracts of $S$. bernensis. $4 \mathrm{M}$ - LiCl core-50 particles from $E$. coli ribosomes were incubated with 'crude methylase' from $S$. bernensis both in the presence and absence of SAM. Then, 50S particles were reconstituted and were supplemented with $30 \mathrm{~S}$ ribosomal subunits. The activity of the resultant $70 \mathrm{~S}$ ribosomes was assayed $(a)$ in synthesis of polyphenylalanine and $(b)$ in uncoupled hydrolysis of GTP dependent on factor EF-G. Control incubations received DMSO; otherwise drugs were added at the indicated molar excesses over ribosomes. Incubations without SAM: $O$, controls; $\square$, berninamycin $(100: 1) ; \Delta$, thiostrepton $(3: 1) ; \nabla$, micrococcin $(3: 1)$. Incubations with SAM: controls - indistinguishable from results with thiostrepton $(100: 1)$, micrococcin $(100: 1)$ and (in $a)$ berninamycin $(100: 1)$; (in $b$ ), berninamycin $(100: 1)$.

Table 4. Effect of S. bernensis 'crude methylase' on binding of $\left[{ }^{35} S\right]$ thiostrepton to complexes of $23 S$ RNA with protein $L 11$

\begin{tabular}{|c|c|c|}
\hline \multirow[b]{2}{*}{$\begin{array}{l}\text { Time of incubation } \\
\text { (min) }\end{array}$} & \multicolumn{2}{|c|}{ Binding ratio* } \\
\hline & $\begin{array}{l}\text { RNA incubated } \\
\text { with SAM }\end{array}$ & $\begin{array}{l}\text { RNA incubated } \\
\text { without SAM }\end{array}$ \\
\hline 0 & 1.02 & 1.02 \\
\hline 10 & 0.76 & 1.03 \\
\hline 20 & 0.33 & 1.00 \\
\hline 30 & 0.04 & 1.04 \\
\hline
\end{tabular}

Equally important were the observations summarized in Fig. 2(b). Methylation of ribosomal cores by extracts of $S$. bernensis also abolished the effects of the three antibiotics upon uncoupled GTP hydrolysis catalysed by reconstituted ribosomes and factor EF-G. Again, results closely similar to those given in Fig. 2(b) were obtained when core particles were incubated with the purified rRNA methylase from $S$. azureus (data not given).

The above data proved that methylation of one or more constituents of a $4 \mathrm{M}-\mathrm{LiCl}$ core- 50 particle, by an enzyme present in $S$. bernensis, could render the $E$. coli ribosome resistant to berninamycin, thiostrepton and micrococcin. However, they did not prove that, like the 'thiostrepton-resistance methylase' from S. azureus, the S. bernensis methylase acted on 23S rRNA. This was established as indicated in Table 4. Escherichia coli $23 \mathrm{~S}$ rRNA incubated 
Table 5. Substrate specificity of ribosomal RNA methylase activity in extracts of $S$. bernensis

\begin{tabular}{ll}
\multicolumn{1}{c}{ Substrate } \\
(components from $E$. coli) & Stoichiometry of methylation* \\
23S RNA & 0.97 \\
16S RNA & 0 \\
5S RNA & 0 \\
4 M-LiCl core-50 particles & $0 \cdot 84$ \\
5OS ribosomal subunits & $n$ \\
& \\
* pmol [ $\left.{ }^{3} \mathrm{H}\right]$ methyl groups incorporated per pmol substrate at saturation.
\end{tabular}

with crude methylase from $S$. bernensis in the presence of SAM progressively lost the ability to participate, together with protein $\mathrm{L} 11$, in the binding of $\left[{ }^{35} \mathrm{~S}\right]$ thiostrepton. In contrast, drug binding was unaffected when 23S RNA was incubated in the absence of SAM. We concluded that $S$. bernensis possesses a methylase which acts on 23S rRNA and which can determine resistance to thiostrepton.

In a final series of experiments, we utilized [methyl $\left.-{ }^{3} \mathrm{H}\right] \mathrm{SAM}$ as cofactor in order further to characterize the $S$. bernensis methylase. As seen in Table 5, the crude methylase introduced a single methyl group into $E$. coli $23 \mathrm{~S}$ rRNA but was without effect on $16 \mathrm{~S}$ or 5S rRNA. This observation suggested that $S$. bernensis contained a single RNA methylase which determined resistance to the antibiotics employed here. Evidently (Table 5), this enzyme acted on free 23S rRNA and on $4 \mathrm{M}-\mathrm{LiCl}$ core-50 particles (which contain 23S rRNA plus about seven proteins) but not on intact 50S ribosomal subunits. Presumably, the enzyme normally acts on ribosomal RNA at an early stage following (or during) transcription. In this respect, the methylase from $S$. bernensis resembles the 'thiostrepton-resistance methylase' from $S$. azureus (Thompson \& Cundliffe, 1981). Indeed, they may be identical in their action. Thus, $S$. bernensis rRNA was not a substrate for the purified enzyme from $S$. azureus (data not given), an observation which would be rationalized were the two enzymes to act at a common site. To establish this hypothesis would require nucleotide sequence analysis of appropriate RNA fragments but, in support of it, we observed that the methylated residue produced by the action of the $S$. bernensis enzyme is $2^{\prime}-O$-methyladenosine. This same residue is produced by the 'thiostrepton-resistance methylase' of $S$. azureus (Cundliffe \& Thompson, 1979). The identity of the methylated product was established by digestion of $\left[\right.$ methyl $\left.{ }^{3} \mathrm{H}\right] 23 \mathrm{~S}$ RNA with snake venom phosphodiesterase (EC 3.1.4.1) and bacterial alkaline phosphatase (EC 3.1.3.1) followed by paper chromatography in butanol/ammonia solvent and high-voltage paper electrophoresis both at $\mathrm{pH} 3.5$ and at $\mathrm{pH} 9.3$ in the presence of borate (for details, see Cundliffe \& Thompson, 1979).

\section{DIS CUSSION}

Berninamycin interferes with various reactions known (or believed) to occur in the ribosomal A site, although none of its effects yet observed in vitro are particularly dramatic. In contrast, the drug is a potent inhibitor of bacterial protein synthesis in vivo (Reusser, 1969). It therefore remains to be established which effect of berninamycin reflects its primary inhibitory action in vivo and how this is attenuated in vitro. Nevertheless, there are some similarities between the action of berninamycin and that of thiostrepton. In support of this concept, berninamycin inhibited (admittedly weakly) the binding of thiostrepton to the complex of $23 \mathrm{~S}$ rRNA with ribosomal protein L11. Perhaps the most remarkable effect of berninamycin was the stimulation of uncoupled hydrolysis of GTP dependent on ribosomes and factor EF-G, a reaction which was powerfully inhibited by thiostrepton. Curious though this effect may have been, its significance could not be doubted. Thus, it did not occur on ribosomes from a thiostrepton-resistant mutant of $B$. megaterium (which is also resistant to 
berninamycin) and it was abolished on $E$. coli ribosomes by specific methylation of $23 \mathrm{~S}$ RNA. Accordingly, we concluded that stimulation of uncoupled, factor-dependent GTP hydrolysis was one facet of the primary mode of action of berninamycin and that it resulted from binding of the antibiotic to its normal target site within the ribosome. Evidently, only one such site exists since specific monomethylation of 23S rRNA renders ribosomes totally resistant to berninamycin. Similar considerations also apply in the case of micrococcin (see Cundliffe \& Thompson, 1981 a). This antibiotic stimulates uncoupled GTP hydrolysis to an even greater extent than does berninamycin and, unlike the latter, is strikingly similar in structure to thiostrepton (Bycroft \& Gowland, 1978). The precise manner in which the inhibitory effects of berninamycin are linked to its ability to stimulate GTP hydrolysis remains to be established as does the relationship between the ribosomal sites with which berninamycin, thiostrepton and micrococcin interact.

Prior to the present work, RNA-pentose methylase activity, capable of rendering ribosomes resistant to thiostrepton, had been observed only among those actinomycetes which produce the thiostrepton-group of antibiotics (Thompson \& Cundliffe, 1980). These compounds are closely related in structure and resistance is expressed against all members of the group (which includes siomycin, sporangiomycin, thiopeptin and thiostrepton). Even the detection of analogous methylase activity in Streptomyces actuosus, the producer of nosiheptide (multhiomycin), was not altogether surprising (Cundliffe \& Thompson, 1981 b) since, like micrococcin, this antibiotic resembles in structure the greater part of the thiostrepton molecule (Prange et al., 1977). Now, for the first time, an enzyme capable of conferring resistance to thiostrepton has been found in an organism which produces a drug not obviously related in structure to thiostrepton. Presumably, therefore, it is significant that berninamycin affects the binding of thiostrepton to ribosomes. Plausibly, the drugs interact with related sites which can be distorted, by specific monomethylation of $23 \mathrm{~S}$ rRNA, so as to prevent the attachment of either drug or to render bound drug ineffective. This certainly happens in $S$. azureus and we suggest that a similar situation obtains in $S$. bernensis. Thus, w. have established that a highly purified preparation of the 'thiostrepton-resistance methylase' from $S$. azureus can also confer ribosomal resistance to berninamycin. This enzyme introduces a single methyl group into 23S rRNA (Thompson \& Cundliffe, 1981). Conversely, methylation of $4 \mathrm{M}-\mathrm{LiCl}$ core-50 particles by a crude extract of $S$. bernensis resulted in resistance of ribosomes to berninamycin, thiostrepton and micrococcin. Moreover, the binding site for thiostrepton could not be reconstituted following methylation of $23 \mathrm{~S}$ rRNA by $S$. bernensis crude extract. That same extract introduced only a single methyl group into total rRNA of $E$. coli. The substrate was $23 \mathrm{~S}$ rRNA and the methylated residue produced was $2^{\prime}-O$-methyladenosine. This is also the product of the $S$. azureus methylase. Therefore, although it is difficult to establish the point unequivocally (and we have not done so), we suggest that the methylase which determines resistance to thiostrepton in $S$. bernensis acts in similar fashion to the 'thiostrepton-resistance methylase' of $S$. azureus. Certainly, failure of the latter enzyme to act on $S$. bernensis rRNA is consistent with this hypothesis. Given that action of the 'thiostrepton-resistance methylase' of $S$. azureus also renders ribosomes resistant to berninamycin, we see no reason to postulate that resistance to the two drugs is determined separately in $S$. bernensis.

We have commented previously (Thompson \& Cundliffe, 1981) on the conceptual problem of understanding how genes responsible for antibiotic production congregate in appropriate combinations with those which determine antibiotic resistance. In general terms, this paradox is readily resolved if certain gene products possess multiple functions. For example, the 'thiostrepton-resistance methylase' of $S$. azureus might also be involved in thiostrepton production. However, given the structure of thiostrepton and the known specificity of the enzyme, we previously thought this unlikely. Now that the same enzyme (or at least a closely related one) has been found in $S$. bernensis, it remains to be seen whether any other common role will be found for it in the two organisms. 
This work was supported by a Project Grant from the Medical Research Council (to E. C.). We thank Teddy Bedlington for enthusiastic assistance.

\section{REFERENCES}

Bergy, M. E., Coats, J. H. \& Reusser, F. (1972). Antibiotic berninamycin. Chemical Abstracts 77, 150582v. (US Patent 3689639.)

BYCrofT, B. W. \& Gowland, M. S. (1978). The structures of the highly modified peptide antibiotics micrococcin $\mathrm{P}_{1}$ and $\mathrm{P}_{2}$. Journal of the Chemical Society, Chemical Communications, 256-258.

Cundliffe, E. (1978). Mechanism of resistance to thiostrepton in the producing-organism Streptomyces azureus. Nature, London 272, 792-795.

Cundliffe, E. \& Thompson, J. (1979). Ribose methylation and resistance to thiostrepton. Nature, London 278, 859-861.

Cundliffe, E. \& Thompson, J. (1981 a). Concerning the mode of action of micrococcin upon bacterial protein synthesis. European Journal of Biochemistry $118,47-52$.

Cundliffe, E. \& Thompson, J. (1981b). The mode of action of nosiheptide (multhiomycin) and the mechanism of resistance in the producing organism. Journal of General Microbiology 126, 185-192.

Cundliffe, E., Dixon, P., Stark, M., StöFfler, G., Ehrlich, R., StöfFler-MEIlicke, M. \& CANNON, M. (1979). Ribosomes in thiostrepton-resistant mutants of Bacillus megaterium lacking a single 50S subunit protein. Journal of Molecular Biology 132, $235-252$.

DiJK, J. \& LitTlechild, J. (1979). Purification of ribosomal proteins from Escherichia coli under non-denaturing conditions. Methods in Enzymology 59, 481-502.

Dixon, P. D., Beven, J. E. \& Cundliffe, E. (1975). Properties of the ribosomes of antibiotic producers: effects of thiostrepton and micrococcin on the organisms which produce them. Antimicrobial Agents and Chemotherapy 7, 850-855.

Gale, E. F., Cundliffe, E., Reynolds, P. E., Richmond, M. H. \& WARING, M. J. (1981). Molecular Basis of Antibiotic Action, 2nd edn, ch. 6, pp. 402-547. Chichester \& New York: John Wiley.

LIESCH, J. M. \& RINEHART, K. L., JR (1977). Berninamycin. 3. Total structure of berninamycin A1,2. Journal of the American Chemical Society 99, 1645-1646.

Modolell, J., VazQuez, D. \& MonRo, R. E. (1971). Ribosomes, G-factor and siomycin. Nature New Biology 230, 109-112.

Pedersen, F. S., Lund, E. \& KJeldgaArd, N. O. (1973). Codon specific, tRNA dependent in vitro synthesis of ppGpp and pppGpp. Nature New Biology 243, 13-15.
PestKa, S. (1970). Thiostrepton: a ribosomal inhibitor of translocation. Biochemical and Biophysical Research Communications 40, 667-674.

Prange, T., Ducruix, A., Pascard, C. \& Lunel, J. (1977). Structure of nosiheptide, a polythiazolecontaining antibiotic. Nature, London 265, 189190.

REUSSER, F. (1969). Mode of action of berninamycin. An inhibitor of protein biosynthesis. Biochemistry 8 , 3303-3308.

STARK, M. \& Cundliffe, E. $(1979 a)$. On the biological role of ribosomal protein BM-L11 of Bacillus megaterium, homologous with Escherichia coli ribosomal protein L11. Journal of Molecular Biology 134, 767-779.

StARK, M. \& CundlifFe, E. (1979b). Requirement for ribosomal protein BM-L11 in stringent control of RNA synthesis in Bacillus megaterium. European Journal of Biochemistry 102, 101-105.

Stark, M. J. R., CundlifFe, E., DiJk, J. \& STÖFFLer, G. (1980). Functional homology between Escherichia coli ribosomal protein L11 and Bacillus megaterium protein BM-L11. Molecular and General Genetics 180, 11-15.

Thompson, C. J., WARD, J. M. \& Hopwood, D. A (1980). DNA cloning in Streptomyces: resistance genes from antibiotic-producing species. Nature, London 286, 525-527.

Thompson, J. \& Cundliffe, E. (1980). Resistance to thiostrepton, siomycin and sporangiomycin in actinomycetes that produce them. Journal of Bacteriology 142, 455-461.

Thompson, J. \& Cundliffe, E. (1981). Purification and properties of an RNA methylase produced by Streptomyces azureus and involved in resistance to thiostrepton. Journal of General Microbiology 124, 291-297.

Thompson, J., Cundliffe, E. \& STARK, M. (1979). Binding of thiostrepton to a complex of 23S rRNA with ribosomal protein L11. European Journal of Biochemistry 98, 261-265.

Tori, K., Tokura, K., Yoshimura, Y., Terui, Y., OKabe, K., Otsuka, H., Matsushita, K., INAGAKI, F. \& MIYAZAWA, T. (1981). Structures of siomycin-B and $-C$ and thiostrepton-B determined by NMR spectroscopy and carbon-13 signal assignments of siomycins, thiostreptons and thiopeptin- $\mathrm{B}_{\mathrm{a}}$. Journal of Antibiotics 34, 124-129. 